\title{
Review on hydrogen production technologies from solar energy
}

\author{
M. A.Suárez-González,A.M. Blanco-Marigorta, andJ. A.Peña-Quintana \\ Department of Process Engineering \\ University of Las Palmas de Gran Canaria \\ Edificio de Ingenierías-Tafira Baja,35017 Las Palmas de Gran Canaria (Spain) \\ Tel: +34 928451934 Fax: +34 928458975 \\ e-mail:marco.a.suarez.gonzalez@gmail.com, ablanco@dip.ulpgc.es, ipena@dip.ulpgc.es
}

\begin{abstract}
This article overviews the available technologies for hydrogen generation using solar energy as main source. Photochemical, electrochemical and thermochemical processes for producing hydrogen with solar energy are analysed from a technological and economical point of view. It is concluded that developments of improved processes for hydrogen production via renewable feedstock are likely to continue in order to reach competitive hydrogen production costs. Hybrid thermochemical processes where hydrocarbons are exclusively used as chemical reactants for the production of syngas and the concentrated solar radiation is used as a heat source, represent one of the most promising alternatives: they combine conventional and renewable energy representing a proper transition towards asolarhydrogen economy.
\end{abstract}

\section{Keywords}

Hydrogen generation, solar energy, electrochemical process, photochemical process, thermochemical process.

\section{Introduction}

The actual energetic situation, with pollution problems, climate change, international conflicts motivated by the resource accessibility, and the run out of fossil fuels, precise new energy production technologies. Among them, those based in hydrogen as energy currency play an important role. In the long term is expected that hydrogen willreplace fossil fuels giving way to a hydrogen economy.

Clean hydrogen production from renewable energy is, no doubt, an important aspect to take into account inside the real launch of this gas as a future energy
carrier.Oursociety demands more and more a "sustainable development", but it has to be remarked that hydrogen technologies can be or not clean technologies depending on theirsources.

Hydrogen production from renewable energies is becoming more prominent. Hydrogen generation from renewable energies emerge as a proper way to store, as chemical energy, the energy coming from the sun.

There are basically three pathways, and their combinations, for producing hydrogen with solar energy: electrochemical, photochemical, and thermochemical. In this paper, their different technologies are reviewed and a brief economical comparison among them is carried out.

This paper represents an abstract of a previous work [1]. Due to the great amount of them, original references are not included here. Please refer to [1] to consult them.

\section{Photochemical Processes}

Photochemical processes use solar light to produce the hydrolysis of water. Nowadays two procedures are known: the photoelectrochemical and the photobiological.

In the photoelectrochemical process, water is split into hydrogen and oxygen in a single step and on a single device. This process differs to a conventional process where solar energy and electrolysis are used independently to separate water components. 
On a photoelectrochemical device, the photovoltaic cell receives the solar energy and is also used as one of the electrodes. The photovoltaic device has to generate enough voltage to split water (at least $1.6 \mathrm{~V}$ ) and its surface has to conduct the electricity, resist the corrosion produced by the electrolyte and catalyze the electrochemical reactions.

Photobiological processes are based in the capacity of some organisms, such as green algae, cyanobacteria, photosynthetic bacteria, and dark fermentation bacteria, to act as biological catalystsin the production of hydrogen from water and different enzymes, such as hydrogenase and nitrogenase.

The great variety of organisms that are susceptible to be used, allows to arisehybridising outlines with photoreactors and fermentators.

Both processes, photoelectrochemical andphotobiologicalprocess,are still under investigation procedures. Their implementation is expected only in the long term.

\section{Electrochemical Processes}

Water electrolysis is a well-known technology.It has already been investigated for many years. An electrical current passes through two electrodes, submerged on an electrolyte, producing water electrolysis.

The process of electrolysis can occur at both ambient temperature and at high temperature. In the last case steam instead of water is the raw material. The process with more development possibilities is the electrolysis at high temperatures.

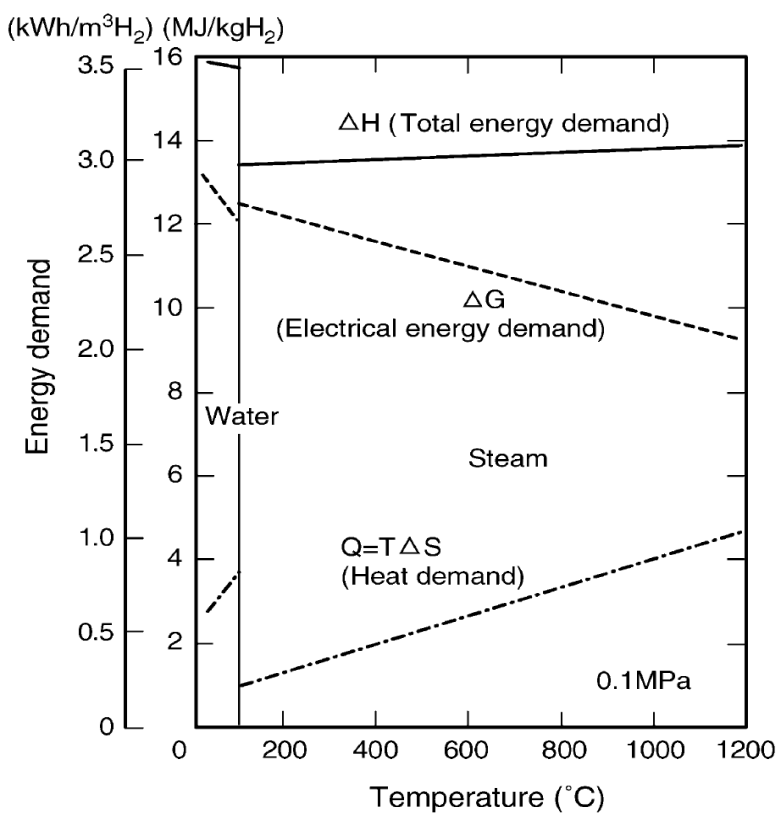

Fig. 1. Energy demand for water and steam electrolysis[2].
The most used technology for electrolysis at high temperatures is the solid oxide cell. It consists of a solid electrolyte, a cathode (where hydrogen is produced) and an anode (where oxygen is released). Water is heated with solar energy before entering the electrolysis cell as steam. The steam is supplied to the cathode, where it decomposes into oxygen ions and hydrogen. The hydrogen is then separated as a product, and oxygen ions move through the solid electrolyte to the anode, where oxygen is also obtained as a product.

The total energy demand for water electrolysis is the sum of electrical and heat energy demands. Fig. 1 shows that electrical energy demand decreases as the temperature rises. The ratio between the electrical energy and the total energy is a $93 \%$ at $100{ }^{\circ} \mathrm{C}$, This value decreases to $70 \%$ when the electrolysis is performed at $1000{ }^{\circ} \mathrm{C}$. The higher the temperature of the reaction, the lower the electrical energy demand in the production of hydrogen.

Electrolyzators for high temperature electrolysis have not been commercialized yet; therefore it is stillan under investigation and development technology.

\section{Thermochemical Processes}

Thermochemical methods for the production of hydrogen from solar energyinclude: direct thermolysis of water, thermochemical cycles and cracking, reforming and gasification of hydrocarbons. These processes use concentrated solar radiation as high temperature heat source to carry the endothermic reaction out. Different devices are used to reach high solar concentration ratios: parabolic discs, tower systems and solar furnaces; with parabolic troughs, the necessary temperature level cannot be reached.

\section{A.Thermochemical Cycles}

In thermochemical cycles water is split up into hydrogen and oxygen through separated chemical reactions using intermediate elements that are recycled within the process. They give the possibility to operate at lower temperatures compared to thermolysis process with the same global reaction. Moreover, it is easy to achieve the separation between oxygen and hydrogen, because both of them are obtained in separate reactions.

About 280 thermochemical cycles exist. The thermochemical solar cycles that are mainly being investigated nowadays are: the sulphur-iodine cycle (in which the coupled reaction system takes water as an input and through a series of reactions involving sulfur and iodine produces $\mathrm{H} 2$ and $\mathrm{O} 2$ as output), the Westinghousesulphur cycle (where sulphurous acid and 
water are reacted electrolytically to produce hydrogen and sulphuric acid) the UT3's 4-step cycle (based on the hydrolysis of $\mathrm{CaBr} 2$ and $\mathrm{FeBr} 2$ at 1020 and 870 $\mathrm{K})$ andthe more efficient 2-step thermochemical cycles using metal oxide redox reactions (e.g. $\mathrm{ZnO} / \mathrm{Zn}$ )[3].

Thermochemical cycles have now high hydrogen production costs.These processes could, however, become more competitive as long as the prize of fossil fuel rises and also with the industrial scale production of the devices.

\section{B.Hybrid Processes}

Hybrid processes are those in which solar energy is used as heat source of the process and fossil fuels are used exclusively as chemical reactants.

The advantages of these processes compared to the conventional ones, where fossil fuels are used both as heat and chemical source, are:

- Fuel saving.

- No contamination of the products by the combustion sub-products.

- The dumping of pollutants to the environment is avoided when carbon capture and storage exists.

- A higher thermal efficiency is obtained due to direct radiation.

The hybrid use of fossil fuels with solar energy could, consequently, extend the useful life of the fossil fuel resources leading to a bit more time to work on the investigation of a permanent sustainable energy source.

\section{- Solar cracking}

Solar cracking (generally, of methane) is the thermal decomposition of a hydrocarbon (methane) into hydrogen and elemental carbon in a free-oxygen environment, using concentrated solar energy (Fig. 2 - upper box). When the process takes place over a solid fuel it is known as pyrolisis.

Carbon produced in this process is marketable. This is a determinant factor to decrease the hydrogen production costs within this process as far as carbon selling price increases.

There are several reactor designs for the cracking of natural gas such as the Abanades \& Flamant, which has a hydrogen production efficiency of $65 \%$ at about $1800 \mathrm{~K}$, as Hirsch \& Steinfeld with a production of $67 \%$ at 1600 $\mathrm{K}$, or as NREL with a hydrogen production of $90 \%$ at $2100 \mathrm{~K}[1]$.

\section{- Solar reforming/gasification}

The main difference between solar reforming and the conventional reforming process lies in the reactor. A solar reactor is a special designed device which uses the concentrated solar radiation to obtain the necessary heat for driving the reaction. An example would be the volumetric reactor used in the SOLREF (SOLar steam REForming of methane rich gas for synthesis gas production) project, where an $80 \%$ of hydrogen production efficiency is reached at about $1000-1100 \mathrm{~K}$ [1].

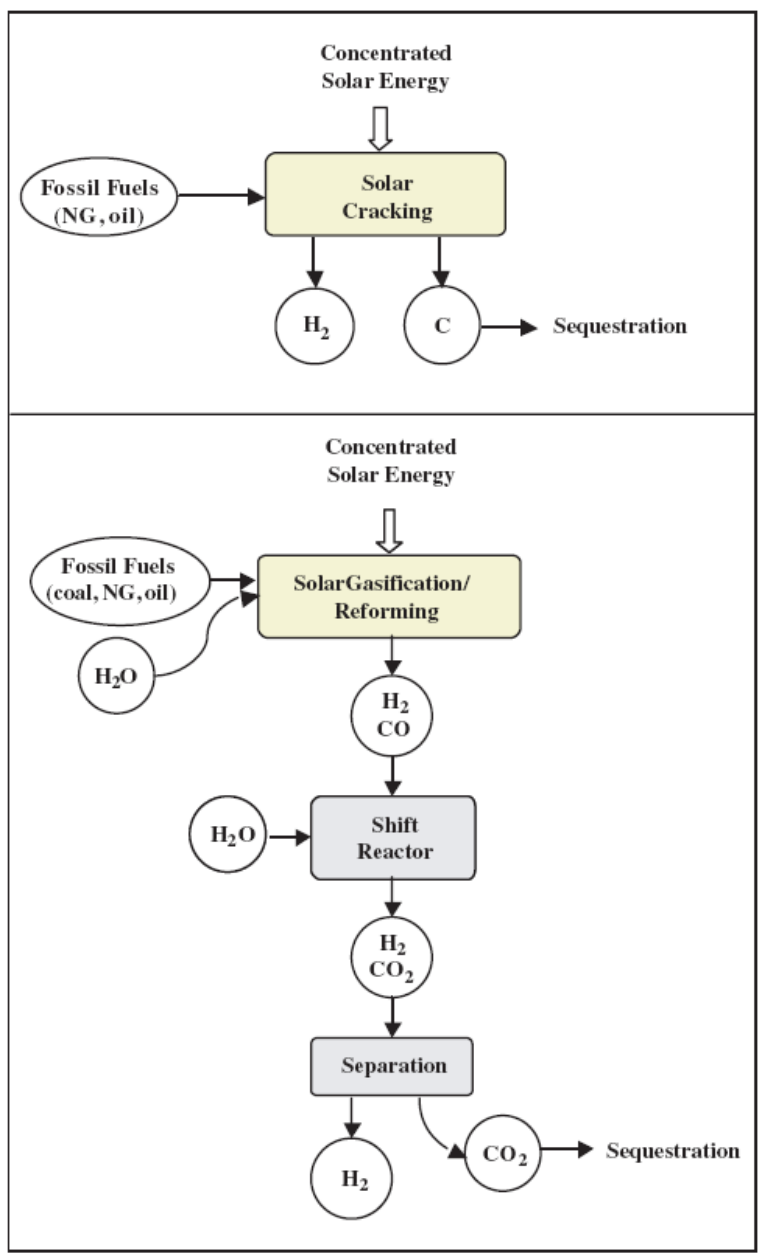

Fig.2. Schematic of solar thermochemical routes for $\mathrm{H}_{2}$ production using fossil fuels and $\mathrm{H}_{2} \mathrm{O}$ as chemical source: solar cracking (upper box), and solar reforming and gasification (lower box) [3].

As in a conventional reforming process, natural gas is pre-treated and synthesis gas is cleaned when pure hydrogen is willing to be produced. The cleaning of the syngas takes place in a $\mathrm{CO}$ conversion reactor, where $\mathrm{H}_{2}$ and $\mathrm{CO}_{2}$ are produced. The following step is the separation of $\mathrm{H}_{2}$ (e.g. with a pressure swing adsorption device).Then, $\mathrm{CO}_{2}$ is separated and stored (optional, but recommended) (Fig. 2 - lower box).

One of the most interesting processes to integrate solar 
energy is membrane reforming. In membrane reforming reactors, the reforming reaction takes place in tubular reactors that consist of selective membranes, generally made of palladium, which separate the hydrogen as it is produced.

The principal advantages of a solar membrane reformingprocesscompared to the conventional reforming process are:

- The reforming is carried out at well lower temperature, about $550{ }^{\circ} \mathrm{C}$. This means a significant reduction in the energetic consumption. Low temperature reactors also use less costing materials for the reforming reactor tubes.

- Hydrogen is obtained with a higher purity, due to the high efficientmembrane separation process.

- Methane conversions of up to $90 \%$ can be reached, due to high hydrogen extraction through the membrane.

- A big part of the $\mathrm{CO}-\mathrm{CO}_{2}$ conversion is produced inside the reactor itself.

- Emissions are reduced up to a $34-53 \%$ due to the use of concentrated solar energy to obtain the process heat.

Gasification process is similar to reforming, but heavy hydrocarbons are used as feedstock. These are transformed into cleaner fuels for a combined cycle or the process could carry on to produce hydrogen.A solar gasification plant using petroleum coke has been tested in the Solar Platform of Almería (Spain).The reactor has reached a hydrogen production efficiency of $60 \%$ working at $1500 \mathrm{~K}[1]$.

\section{Economic comparison and outlook}

Table I shows the projected costs (in the long term) of hydrogen production $(€ / \mathrm{t}$ de $\mathrm{H} 2)$ using the commercial available technologies presented in this paper. Costs values of hydrogen production from other future renewable options and actual large-scale commercial plants consuming fossil fuels are also presented in Table I for comparison purposes.

Steam methane reforming (SMR) is nowadays the more competitive available technology for the production of hydrogen from an economical point of view. Table I shows how the conventional SMR has production costs of $1200 € / t$ of hydrogen. With carbon capture and storage technologies (CCS), SMR become more expensive. However the development and implementation of CCS systems is a pre-requirement for the hydrogen scenario in order to meet the ambitious goals of the world environmental policy.
Among related technologies for production of hydrogen with solar energy, only solar methane steam reforming could become cost competitive. Nevertheless, the costs of this technology depend on natural gas prices. Same consideration corresponds to solar methane cracking. It is expected that their high hydrogen production cost will noticeably decrease as prices of methane and carbon decrease. Within this scenario, an opportunity for those regions with high solar potential appears. The middle East, the north and south of Africa, the south of Spain and the Canary islands (among others), have the possibility to became world powers in solar hydrogen generation. A proper policy could help not only the production of hydrogen for internal consumption, but also, in the long term, the export of intercontinental energy to other hydrogen markets (Europe, USA, Asia, etc.).

Table I.-Projected costs (long term) of hydrogen production ( $€ / \mathrm{t}$ de $\mathrm{H}_{2}$ ) [4].

Current process designs and small scale pilot plants

\begin{tabular}{ll}
\hline Solar hybrid sulphur cycle & 1900 \\
Solar sulphur-iodine cycle & 2000 \\
Solar metal/metal oxide cycle & 3500 \\
Solar high temperature electrolysis & 4667 \\
Solar methane cracking & 1767 \\
Solar methane steam reforming & 1633
\end{tabular}

Other future renewable options

Biomass gasification 1067

Alkaline electrolysis using photovoltaic

power

Alkaline electrolysis using solar thermal power

Alkaline electrolysis using wind power

Large-scale commercial plants consuming fossil fuels

\begin{tabular}{ll}
\hline Methane steam reforming without CCS & 1200 \\
Methane steam reforming with CCS & 1333 \\
Coal gasification with CCS & 1400 \\
\hline
\end{tabular}

Other future renewable options for hydrogen generation cannot be competitive, apart from biomass gasification. However, biomass is mainly used in the production of biofuels (as transport fuel or as feedstock in cogeneration plants). Therefore, a limited potential of this type of hydrogen production technology is expected.

Taking into account previous considerations, the massive hydrogen production is expected to be based in fossil fuels even after year 2030. In this way, the choice of a hybrid transition solar/fossil technology in the production of hydrogen is justified. 


\section{Conclusions}

Nowadays, almost the totality of the hydrogen is produced from fossil fuels. In the medium term, the hybrid utilisation of fossil fuels with solar energy could extend the useful life of the fossil fuel resources. And in the long term, an energy system based on hydrogen will have to use both renewable energy sources and renewable feedstock to reach the goal of becoming a sustainable energy system.

\section{References}

[1] Suárez González, M. A. (2010). Estudio de la producción de hidrógeno a partir de energía solar - PFC.Las Palmas de Gran Canaria: Universidad de Las Palmas de G. C.

[2] Hino, R., Haga, K., Aita, H., \&Sekita, K. (2004). R\&D on hydrogen production by high-temperature electrolysis of steam. Nuclear Engineering and Design.

[3] Steinfeld, A. (2005). Solar thermochemical production of hydrogen - a review. Solar Energy, 78, 603-615.

[4] Pregger, T., Graf, D., Krewitt, W., Sattler, C., Roeb, M., \& Möller, S. (2009). Prospects of solar thermal hydrogen production processes. International Journal of Hydrogen Energy, 34, 4256-4267. 